\author{
Military Technical \\ College \\ Kobry El-Kobbah, \\ Cairo, Egypt
}

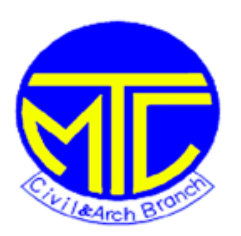

\title{
Structural Performance of Strengthened Box Steel Beams with composite materials
}

\author{
El-Taly B., \\ Lecturer in Civil Engineering Department Engineering, Minoufia University, Egypt.
}

\begin{abstract}
The main objective of the current study is estimate the structural performance of box steel beams strengthened with composite materials. Eight steel box beams (typical beam and seven strengthened beams) were tested in four-points loading. The beam samples are 50x50x1000 mm. Four out of the seven beams were strengthened with steel elements. The other three beams were strengthened with composite materials; CFRP and GFRP flexible sheets. The sheets were wrapped around the whole section of beams at the critical locations. The tested beams also were simulated by the Finite Element (FE) method using ANSYS program. The numerical results in terms of load-deflection curves, load-strain curves and failure modes were compared with experimentally measured data. Also the normal stresses distribution for the eight beams as obtained from the numerical model were presented. Additionally the comparisons between the results of the eight beams were presented and discussed. From these results, it was observed that the predicted FE results are in good agreement with the experimental results. Also the experimental results showed that the failure in the strengthened beams with carbon fiber occurred in the top flange and the upper part of the two webs due to debonding and breakage in CFRP.
\end{abstract}

Keywords: Box steel beam, Composite materials, Finite element analysis; Non-linear analysis

\section{Introduction}

The conventional method of retrofitting steel bridges and structures involves bolting or welding additional elements such as steel plates or channels to the structure (refer to Bakht et al, $\left.1979^{(2)}\right)$. This method has a number of constructability and durability drawbacks. These drawbacks include increasing time consuming, losing steel cross section in case of bolting, happening fatigue in case of welding, steel corrosion. Also applying steel plates requires heavy lifting equipment and it causes increasing in the structure dead loads (see Shaat, $2007^{(21)}$ ).

Recently a second method has become more popular method for strengthening and repairing steel, concrete and steel-concrete composite structures using Fiber Reinforced Polymer (FRP). FRP is a composite material and it has high tension strength, light weight and high resistance to corrosion. It is produced from Carbon Fiber Reinforced Polymer (CFRP) or Glass Fiber Reinforced Polymer (GFRP). FRP rigid plates and flexible sheets are available and can easily be applied to the metallic surface. FRP flexible sheets in particular offer a unique advantage of being able to conform to complex and curved surfaces. CFRP material is classified according to 
its elastic modulus to Standard Modulus (SM)-CFRP, High Modulus (HM)-CFRP and Ultra High Modulus (UHM) -CFRP. SM-CFRP has an elastic modulus value less than that of steel $(E C F R P<200 \mathrm{GPa})$ while HM-CFRP has elastic modulus ranging between $200 \mathrm{GPa}$ and 400 GPa. CFRP material with high value of elastic modulus larger than $400 \mathrm{GPa}$ was referred to as Ultra High Modulus-CFRP (refer to Schnerch et al, $2007^{(20)}$, Tavakkolizadeh and Saadatmanesh, $2003^{(24)}$, Al-Saidy et al, $2005^{(1)}$, Photiou et al, 2006a ${ }^{(17)}$, Photiou et al, 2006b ${ }^{(18)}$, Michael. 2005 (14) (10) (22) (24)

, Jagtap et al Shaat and Fam, 2006 and Shaat and Fam, 2009 ).

FRP is fixed in the steel using adhesive (resin) material. The bond at the interface between the two materials controls in the transferring force between FRP and steel. Bond performance is effected by several factors such as type of fibers and adhesive (resin), surface preparation, thickness of adhesive, and thickness of FRP laminate, the bonded length and width (Lam et al, $\left.2004^{(11)}\right)$.

Various researches studied the retrofitting steel I beam by applying CFRP plate to the beam lower flange. The results of these researches showed that the presence of the CFRP plate can help to increase the ultimate strength and post-elastic stiffness of typical I-steel beams (especially when a high modulus CFRP is used). This means that the strains in the beam are reduced under the same load and the first yielding of the beam is delayed (El Damatty et al, 2003
(7), (12) (13) (5)

Lenwari et al, 2006 , Linghoff et al, 2006 and Colombi and Poggi, 2006 ). Various failure modes occurred for such FRP-plated steel beams. Plate end debonding in an FRP-plated steel beam is the famous mode of failure. It is due to high localized interfacial shear stresses and peeling stresses in the vicinity of the plate end. Plate end debonding is more likely to occur when the plate end is farther away from the adjacent support in a case of simply-supported beam (in three- or four-point bending). Plate end deponding can be delayed by increasing the bonded length (see Colombi and Poggi, $2006^{(4),}$ Deng and Lee, $2007^{(6)}$, Teng et al, $2012^{(25)}$, Salama et al, $2011^{(19)}$, Yu et al, $2010^{(26)}$ and Hmidan et al, $2013^{(8)}$ ). Ochi et al, $2011^{(16)}$ investigated experimentally a method to prevent the CRFP plate end debonding. This method is bolted steel plates onto the CFRP strip at the both ends. Their results indicated that the debonding prevention plates effectively work to prevent the debonding of the CFRP strip.

In the current research, eight steel box beams were tested in four-points loading. The current research passes through three different stages. The first stage is studying the structural performance of typical box beam in four-point bending test. The results of the first stage indicated that the failure in the typical beams occurred at the loading positions and their surrounding area (in top flange, lower flange and the two webs). The previous researches in the field of strengthening the steel beams depended on applying the strengthening elements at the tension flange only. The second stage includes four box beams while the third stage includes three box beams. In the second stage, the typical beam is strengthened with different steel configurations at the critical locations (at the loading positions and their surrounding area (in top flange, lower flange and the two webs). In the third stage, the typical beam was strengthened with composite material (CFRP and GFRP sheet). These sheets were wrapped around the whole section of beams at the critical locations. Also the results of tested beams were compared with the results of an employed Finite Element (FE) model by ANSYS program. The results indicated that intermediate debonding followed by fiber breakage at the location of the load (in the top flange and the upper part of the two webs) was occurred in the two strengthened beams with CFRP. 


\section{Experimental work}

\subsection{Specimen details}

A schematic diagram of the cross-section and elevation of the typical beam (BC) and the corresponding strain and dial gages locations are shown in Fig. 1. Eight steel box beams were manufactured and tested in four-point loading. All beams have $1000 \mathrm{~mm}$ length and they were manufactured from a steel plate with $3 \mathrm{~mm}$ thickness. Each beam was manufactured by bending a steel plate to ben -shape to form the upper part of the beam (top flange and the two webs). Then this part was fixed in a lower plate (bottom flange) with $60 \mathrm{~mm}$ width by welding. All details of the tested beams are presented in table 1.

\subsection{Strengthening methods}

Four beams (SB1, SB2, SB3 and SB4) were strengthened by applying steel elements with 3 $\mathrm{mm}$ thickness. SB1 beam was strengthened by welding four longitudinal stiffeners in the typical beam at the location of the two supports and under the applied loads as shown in Fig. 2. SB2 beam was strengthened by welding four $\mathrm{X}$ diaphragms ( $20 \mathrm{~mm}$ width) in the typical beam at the location of the two supports and under the applied loads as shown in Fig. 2. In SB3 beam, the lower flange was strengthened by welding a steel plate (60 mm width and $400 \mathrm{~mm}$ long) at the mid-span of the beam and by two plates $(60 \mathrm{~mm}$ width and $20 \mathrm{~mm}$ long) at the location of the two supports. Additionally steel $\cap$-shape element with $400 \mathrm{~mm}$ long was welded in the beam top flange and the two webs (see Fig. 2). SB4 beam is same as SB3 except that both of the length of strengthening flange steel plate and steel $\cap$-shape element were increased to be $600 \mathrm{~mm}$.

Two layers of a unidirectional woven glass fiber fabric were used in strengthening the sixth tested beam (SB5). Its thickness is $0.172 \mathrm{~mm}$. One layer and three layers of SikaWrap ${ }^{\circledR}-230 \mathrm{C}$ that is a unidirectional woven carbon fiber fabric for the dry application process were used in strengthening SB6 and SB7; respectively. Its thickness is $0.131 \mathrm{~mm}$. Sikadur ${ }^{\circledR}-330$ supplied by Sika Company was used in this study to get sufficient bonding between steel beam and both of carbon fibre and glass fibre. It is a two parts (A and B). Part A is a resin (white) and the second part is a hardener (gray). The mixing ratio was 4:1 (A: B) by weight. Before applying the strengthened materials, the surface was clean from any dust by manual sandblasting. The composite materials were wrapped around the steel beams with $600 \mathrm{~mm}$ long at the critical positions as shown in Fig. 3. Table 2 shows the material properties of the CFRP, GFRP, steel and 
adhesive material.

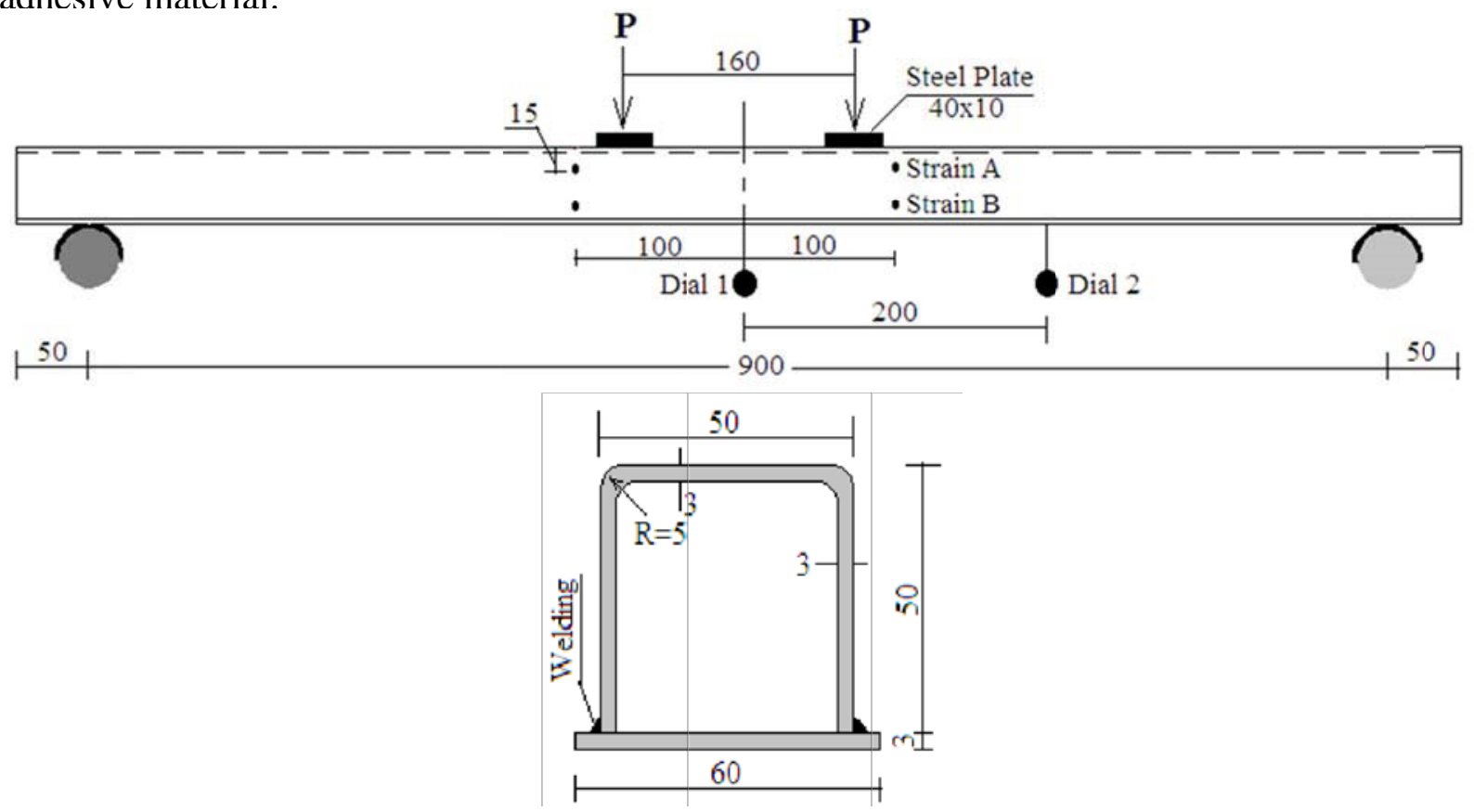

Fig. 1: Typical beam details, strain and dial gage locations (all dimensions in mm)

SB1
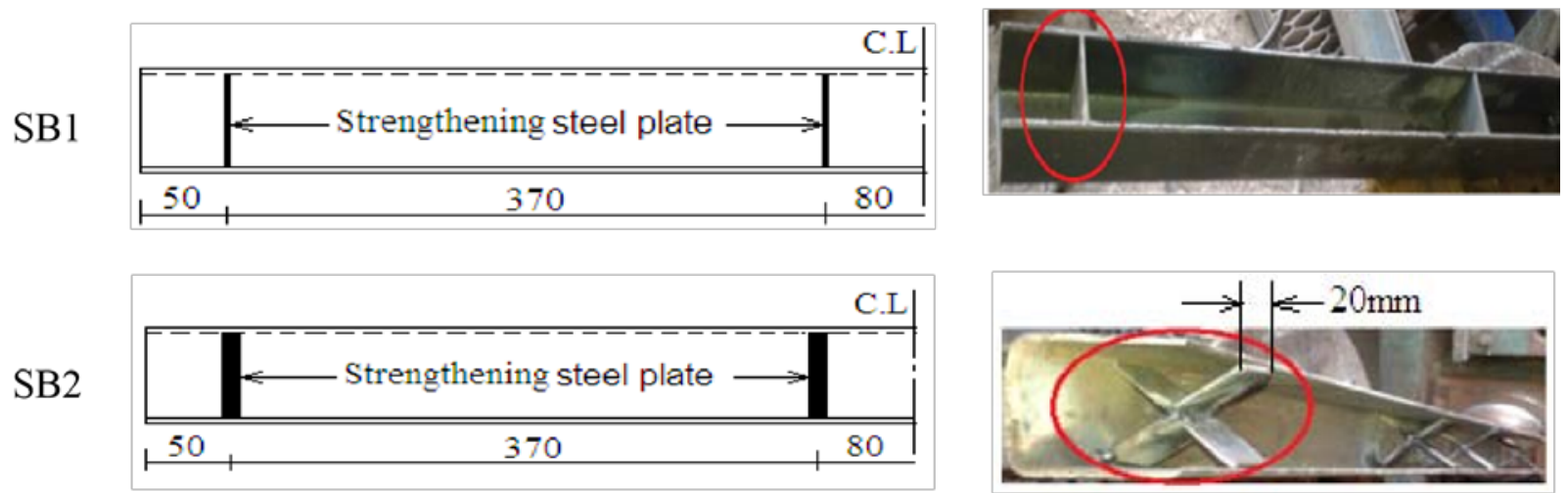

SB3
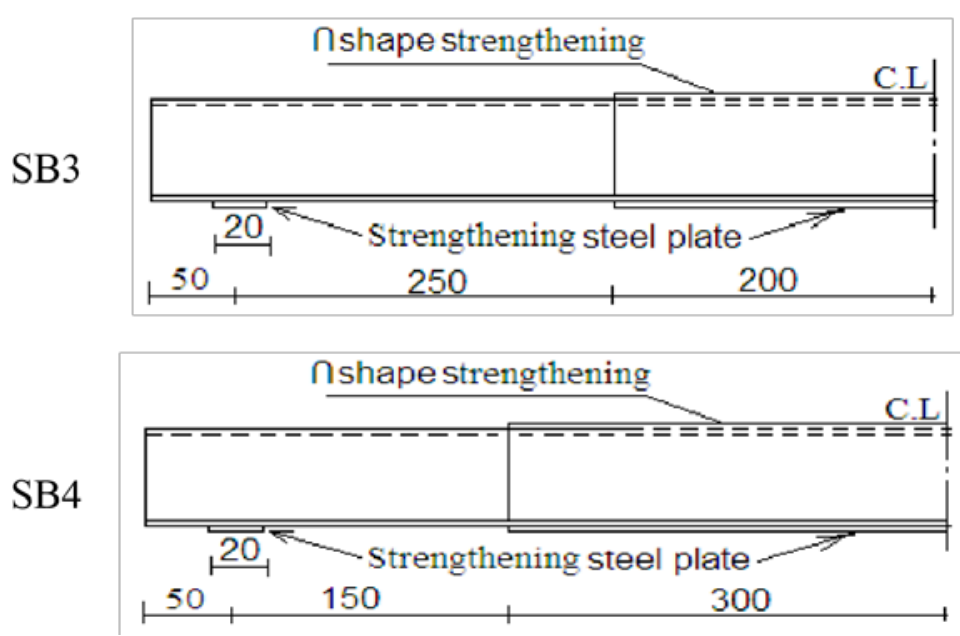

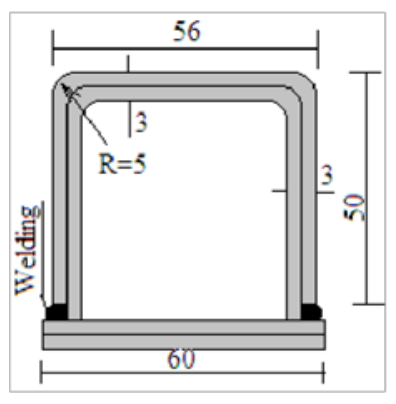

Cross se tion 
Fig. 2: Details of strengthened beams with steel elements (all dimensions in mm)

SB5
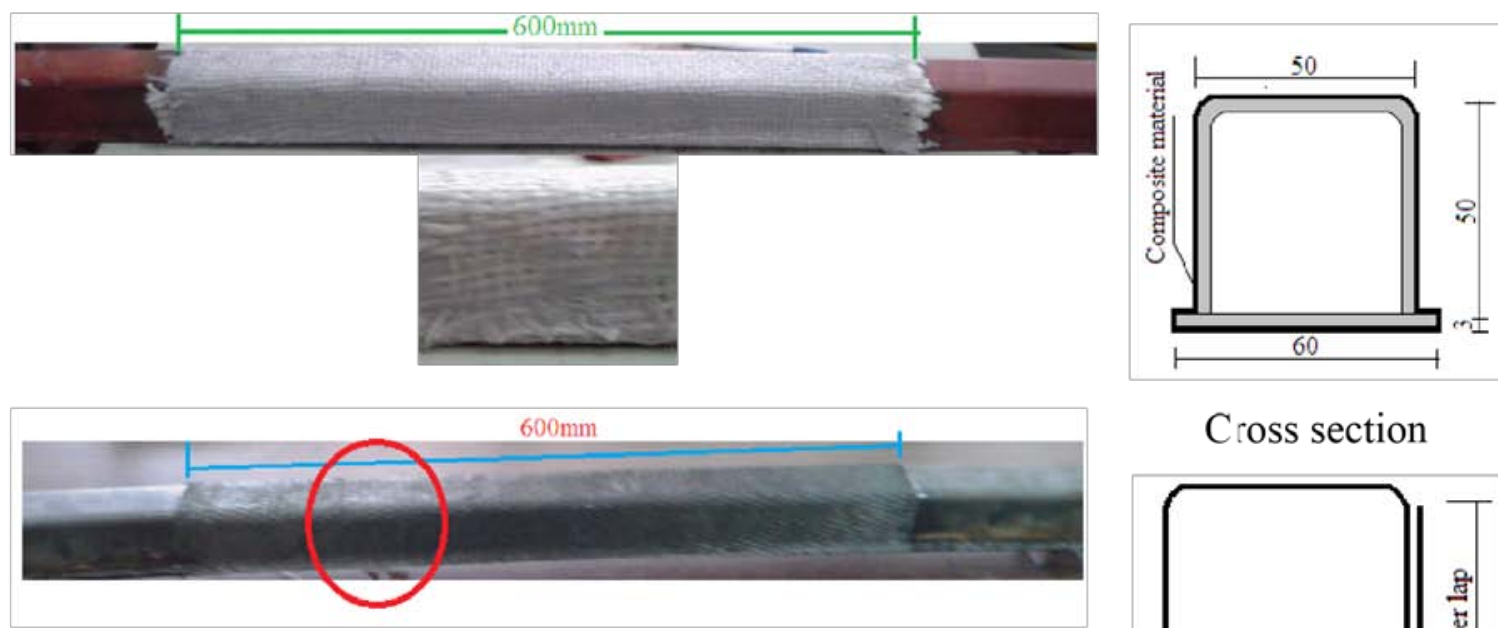

\section{Cross section}

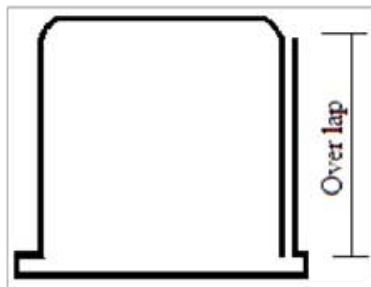

Details

Fig. 3: Details if strengthe ed beams ith composite materials (all dimensions in $\mathrm{mm}$ )

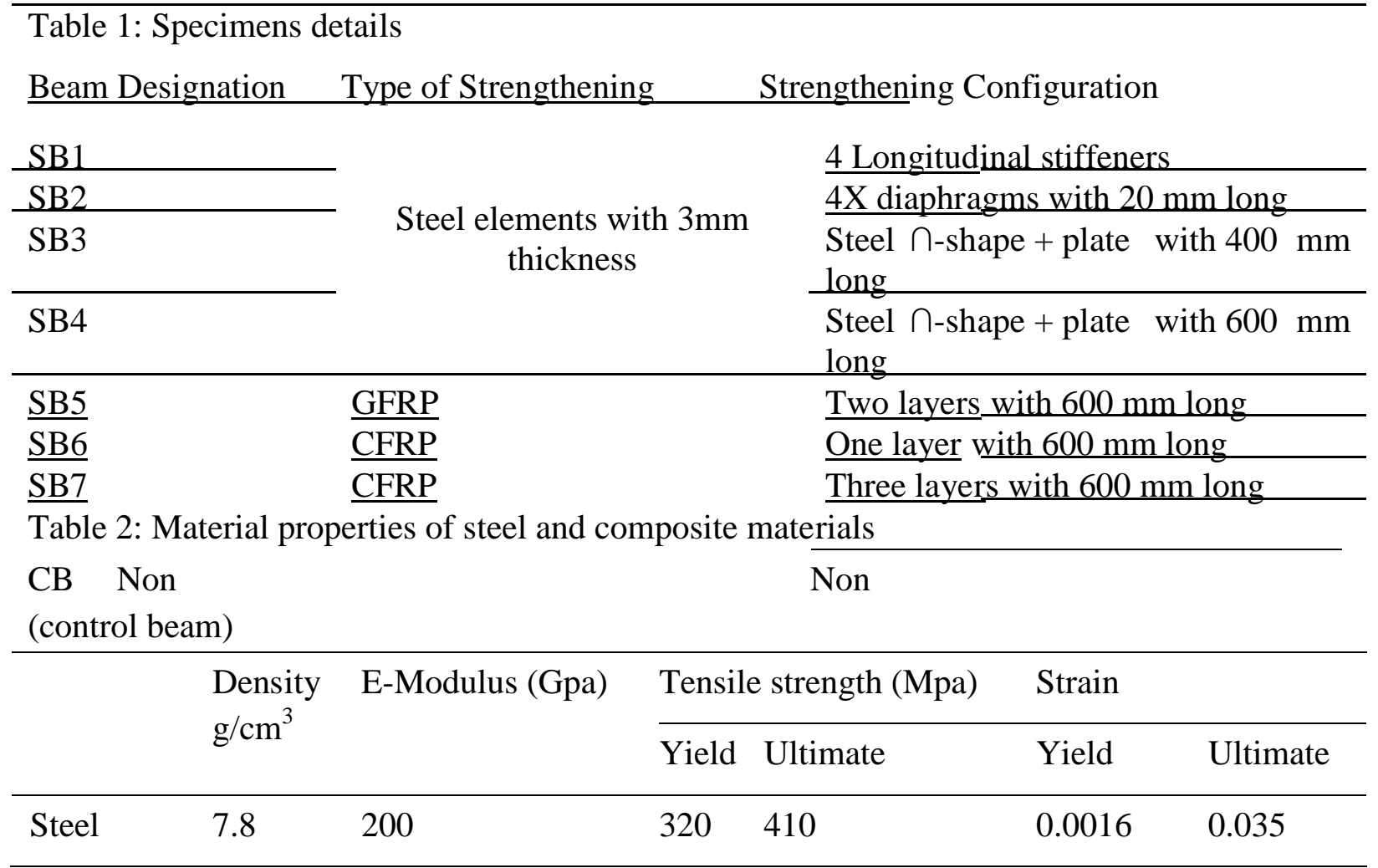




\begin{tabular}{lllll}
\hline CFRP & 1.76 & 238 & 4300 & 0.018 \\
\hline GFRP & 2.56 & 18.3 & 381 & 0.0208 \\
\hline Adhesive & 3.8 & 4500 & 0.009 \\
\hline
\end{tabular}

\section{3. $\quad$ Test setup}

The $1000 \mathrm{~mm}$ long box beam were simply supported with a span of $900 \mathrm{~mm}$ between the two supports and tested under four-points bending static loading with $160 \mathrm{~mm}$ spacing between the two concentrated point loads (see Fig. 1) using Flexural Testing Machine of $100 \mathrm{kN}$ capacity. The beams were tested under an increasing load up to failure at a constant loading rate $(1 \mathrm{kN})$. The behavior of beams was monitored by measuring the deflection at mid-span and at distance $200 \mathrm{~mm}$ from the mid-span using two dial gauges with an accuracy of $0.01 \mathrm{~mm}$. A set of four demec points was fixed in one side of the specimen to allow measuring the strain versus load during the test. Tvicical test set-ub and instrumentation is shown in Fig. 4.

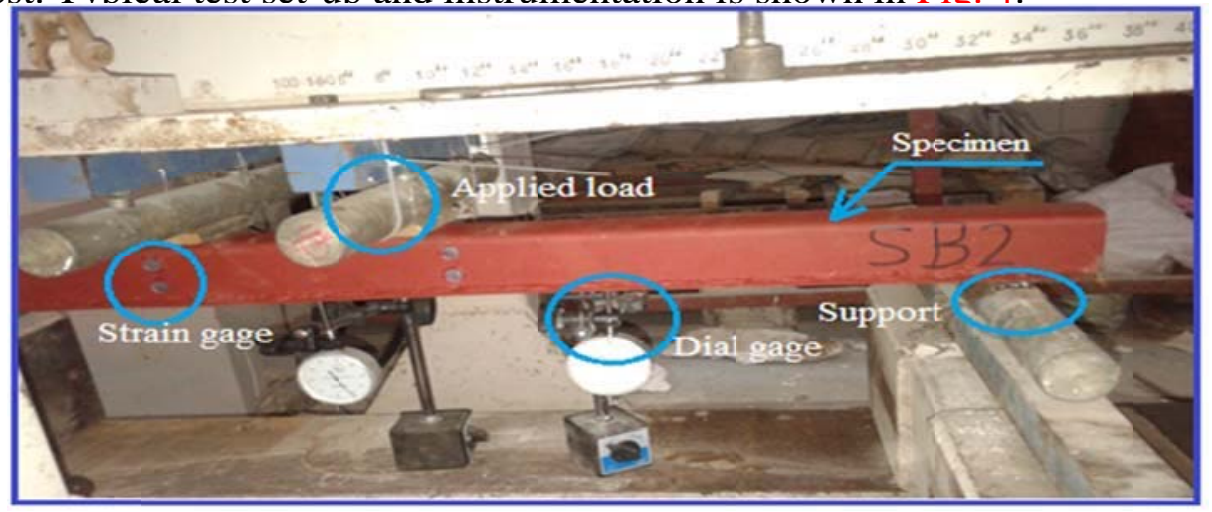

\section{FE Simulation}

Fig. 4: Specimen test

In the present study, finite element program (ANSYS V.12.0) was used to build a three dimensional model to simulate the tested steel beams numerically up to failure. Two types of element were used to represent the tested beam. The first element is Solid185 element (refer to Narmashiri and Jumaat, $2011^{(15)}$ and ANSYS, $2009^{(2)}$ ). This element was used to simulate the steel beam and the strengthening steel elements. Each element is defined by eight nodes. Each node has three degrees of freedom at each node: translations in the nodal $\mathrm{x}, \mathrm{y}$, and $\mathrm{z}$ directions. The element has plasticity, creep, swelling, stress stiffening, large deflection, and large strain capabilities. The second element is Shell181 element and it was used to simulate the composite materials. Shell181 element (ANSYS, $2009^{(2)}$ ) is suitable for analyzing thin to moderately-thick shell structures. Shell181 is a 4-node element with six degrees of freedom at each node: translation in $\mathrm{X}, \mathrm{Y}$ and $\mathrm{Z}$ direction and rotation about $\mathrm{X}, \mathrm{Y}$, and $\mathrm{Z}$ axes. The geometry, node locations, and the coordinate system for used elements are shown in Fig. 5. The FE simulation of the control beam as example is presented in Fig. 6. 

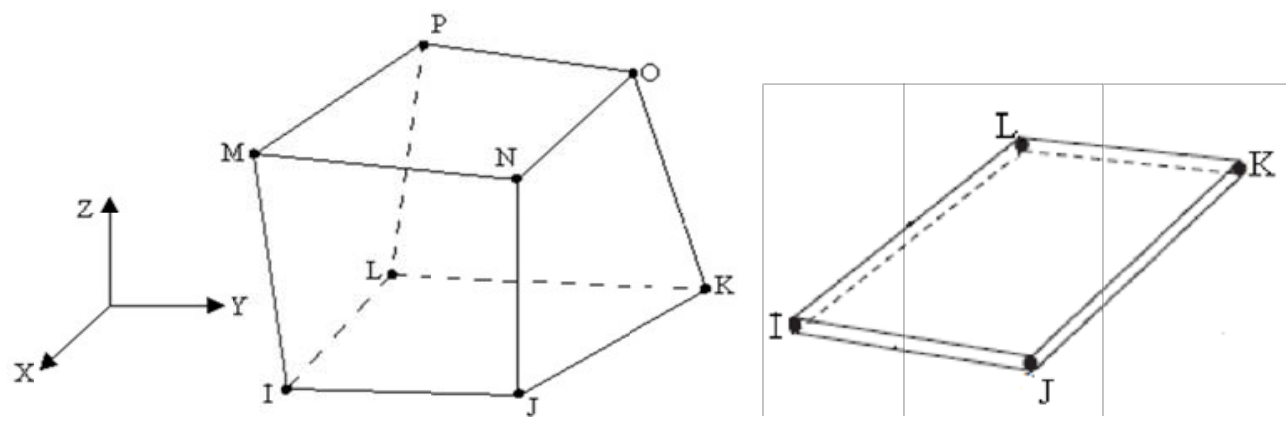

a) Solid185 b) Shell181

Fig. 5: Finite elements geometry

The material nonlinearity was represented by Multi-linear Kinematic Hardening Constants (MKIN). It assumes that the total stress range is equal to twice the yield stresses, so that Bauschinger effect is included. MKIN may be used for materials that obey von Mises yield criteria. The material behavior was described by a stress-strain curve as presented in the experimental work. It starts at the original and it is with positive stress and strain values. The initial slope of the curve is represented the elastic modulus of the material. In the current analysis, load-control technique is used. In this technique, total load is applied to a finite element model. The load is divided into a series of load increments (load steps) during the analysis. ANSYS program uses Newton-Raphson method for updating the model stiffness (refer to ANSYS, $2009^{(2)}$ and Kadhim, $2012^{(9)}$ ).

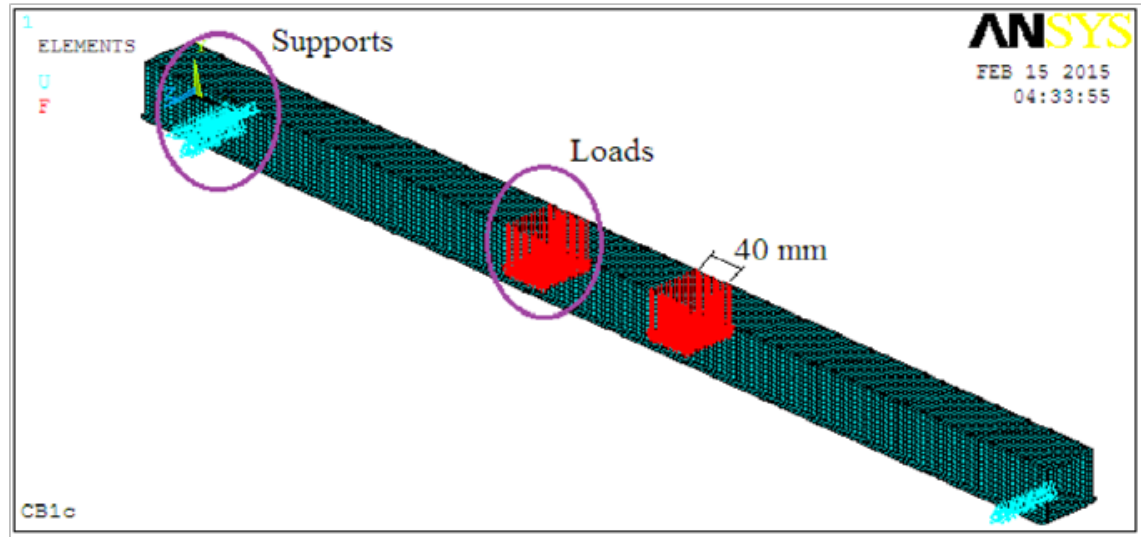

Fig. 6. Geometry of the FE model.

\section{Results and discussion}

At the first, the results of the control beam (the first stage of the research) are presented and discussed. The total applied load-deflection curves at dial (1) and dial (2) points from the experimental work and FE simulation are presented in Fig. 7. This figure showed that the relation between load and the deflection is linear up to $17.5 \mathrm{kN}$ total load and $5.38 \mathrm{~mm}$ corresponding mid-span deflection. After that the plasticity took place and growth in the bottom flange, the top flange and the two webs at the loading positions and their surrounding area, making loaddeflection curve nonlinear up to an applied load equals $19.6 \mathrm{kN}$ and the corresponding deflection at mid-span equals $20.4 \mathrm{~mm}$, after that the deflection increased without significant change in the load. Also from this figure, it can be concluded that the control beam (CB) failed at $20.7 \mathrm{kN}$ and $19.87 \mathrm{~mm}$ total applied and mid-span deflection; respectively from the numerical model. Also this figure indicated that the beam was failed at $17.36 \mathrm{~mm}$ and $17.93 \mathrm{~mm}$ deflection at dial (2) 
point as recorded from the experimental work and numerical model; respectively. The deformed shape at the ultimate load as observed from the experimental work and as obtained from the numerical analysis are showed in Fig. 8. This figure indicated that it is ductile failure mode. The total applied load-strain curves at the two locations of measurements (A and B) are presented in Fig. 9. From this figure, it is observed that the yield started in the two locations (compression and tension) at the same time. From this figures, it can be observed that the experimental and FE simulation results are very close. The normal stresses distribution as obtained from the FE simulation is presented in Fig 10. This figure indicated that the stresses are concentrated under the applied load: compression stresses in the top flange and the upper part of the two webs ( 410 $\mathrm{Mpa}$ ) and tension stresses in the bottom flange and the lower part of the two webs ( 390 Mpa). 


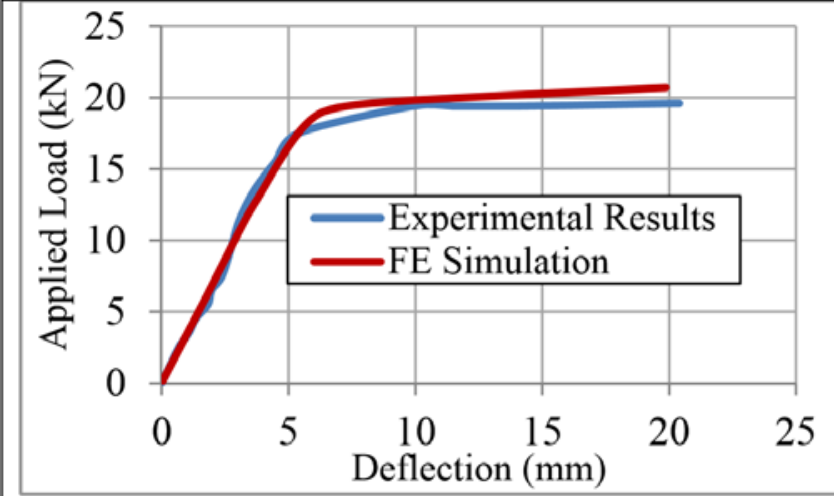

a) At dial gage (1)

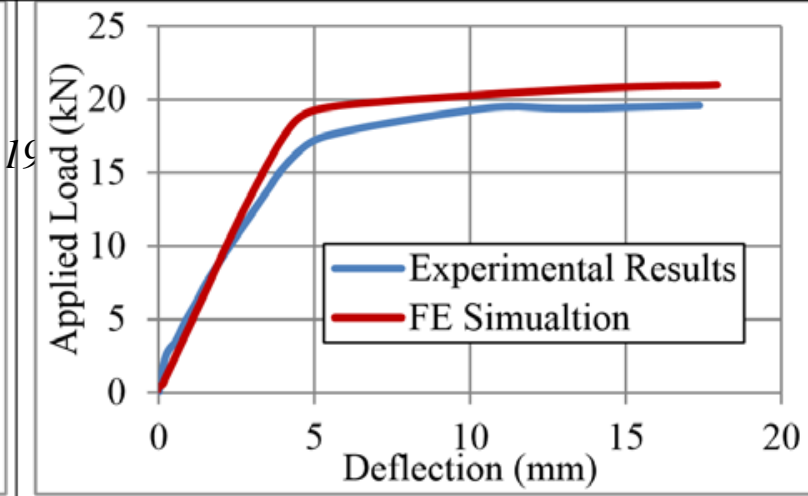

b) At dial gage (2)

Fig. 7 Experimental and FE simulation total load-deflection curves of control beam

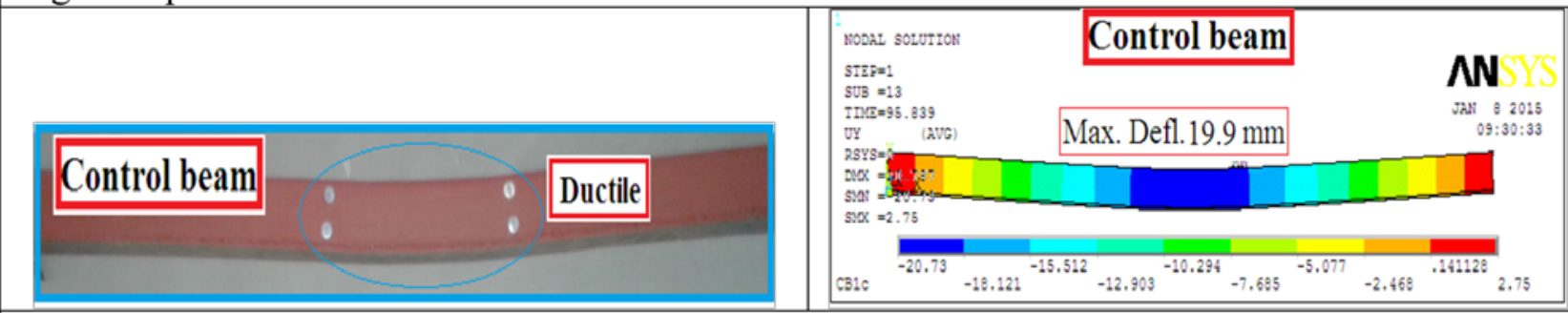

Fig. 8 Failure mode of the control beam (CB)

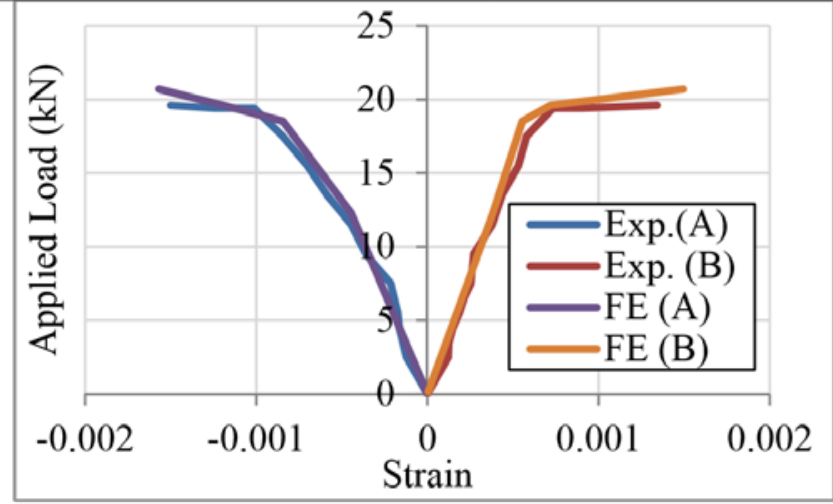

Fig. 9 Load-strain curves of control beam

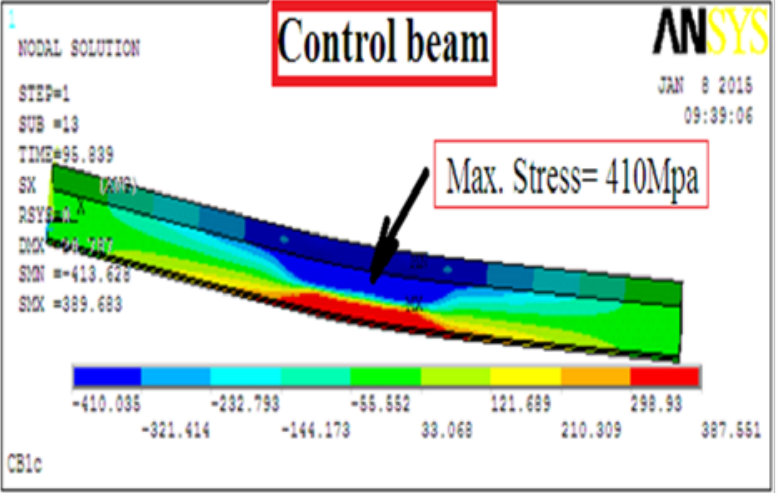

Fig. 10 Numerical normal stresses distribution of $\mathrm{CB}$ beam at the ultimate load

In this section, the results of the strengthened beams are presented and discussed. The comparison between the experimental and the numerical results in terms of load-deflection curves and load-strain curves for strengthened beam with steel elements (second phase of the research) are presented in Fig. 11 and Fig. 12. From these figures, it can be clearly seen that the numerical model gives a good outcome compared to the experimental tests results; the difference between the results not exceed than 15\%. Also Fig. 13 and Fig. 14 present the comparisons between load and deflections and load and strain for strengthened beams with composite materials as obtained from the experimental and FE simulation results. From this figures, it can be noted that the FE simulation results are closed to the experimental results in case of SB5 beam (the steel box beam that was strengthened with GFRP). On the other hand, Fig. 13 and Fig. 14 showed that the experimental and FE simulation results are similar in the linear stage and the difference between the experimental and numerical results are appeared in the nonlinear stage. This is because the failure in the experimental test took place in the compression zone (top flange and upper part of the webs) under the applied load locations due to the occurrence of the debonding and CFRP breakage (see Fig. 15). Also this is due to the consideration of the perfect contact between the steel beam and the composite material in the current numerical model. Additionally Fig. 14 shows that in SB7 beam, shear lag (strain were almost constant while the load continued to increase) appears after $31.5 \mathrm{kN}$ total load in the numerical load-strain curve 
and no shear lag appears in the experimental load-strain curve.
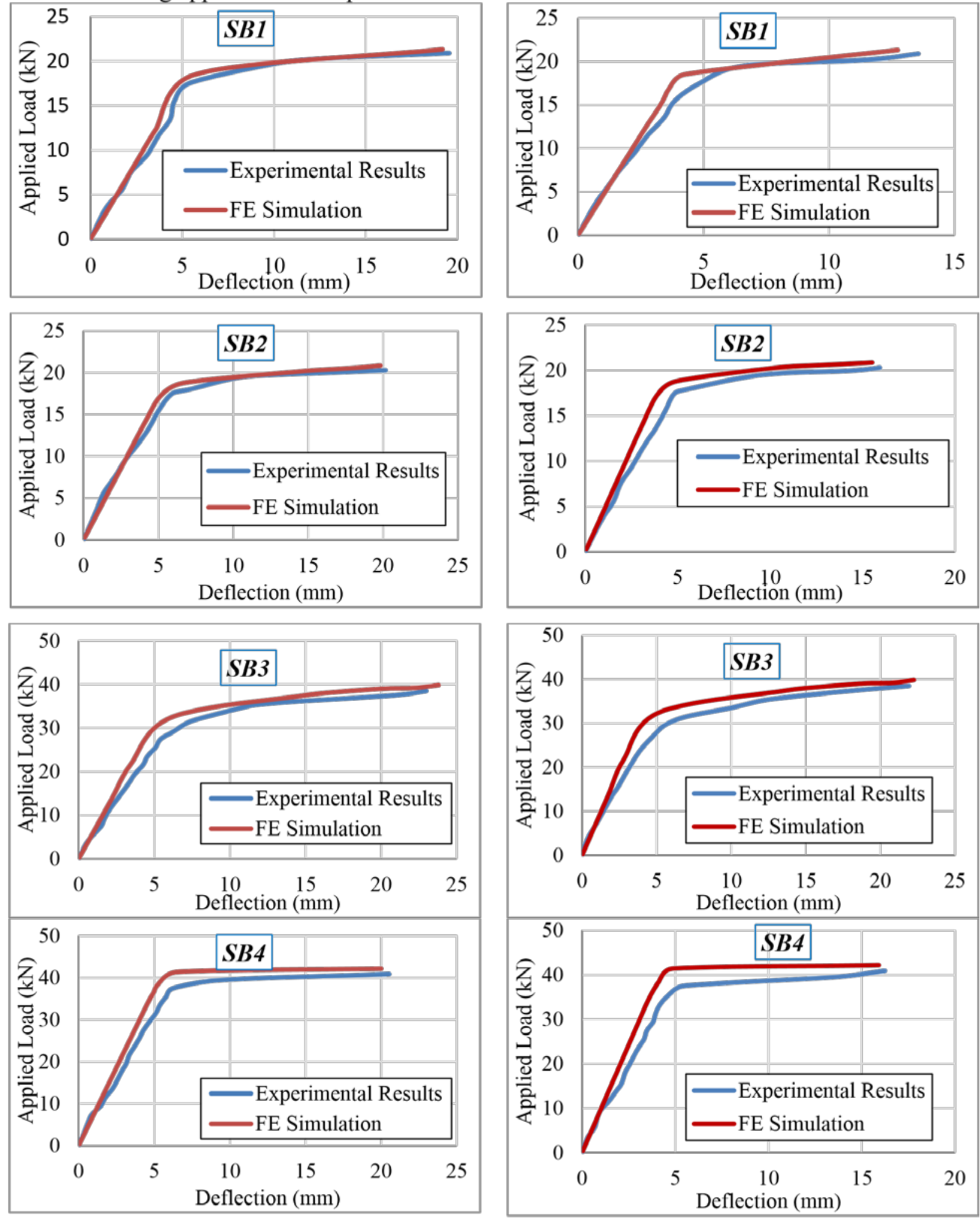

Fig. 11: Experimental and FE simulation total load-deflection curves for strengthened beam with 
steel elements; left at dial 1 and right at dial 2
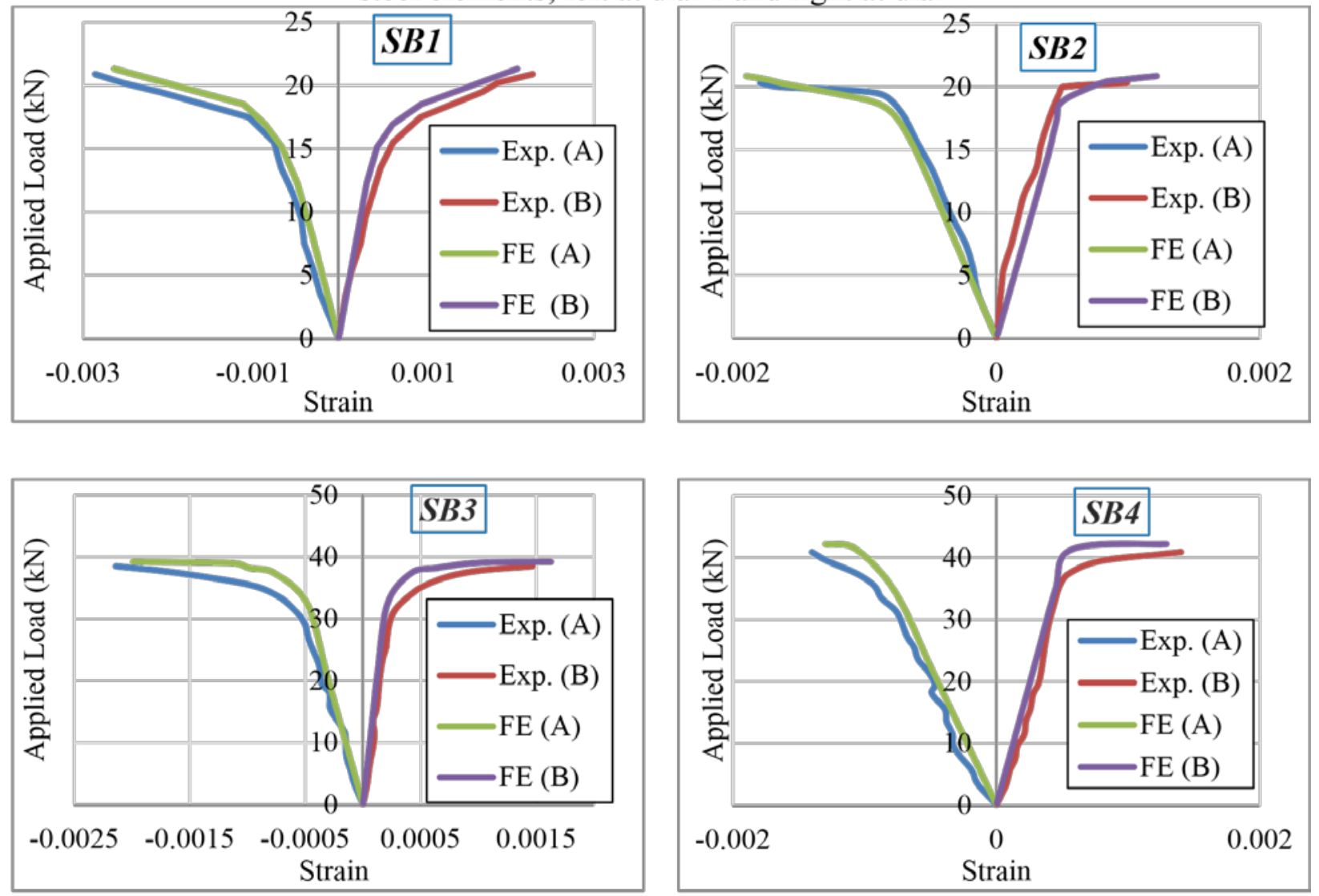

Fig. 12: Experimental and FE simulation total load-strain curves for strengthened beam with steel elements

Fig. 15 shows the failure modes for all straightened beams as obtained from the experimental and numerical works. From this figure, it can be observed that the failure mode for strengthened beams by steel elements is similar to the failure mode of the control beam (ductile failure mode) except the failure mode of SB3 beam. The failure mode of this beam (SB3) is ductile failure mode followed by local failure in the top flange of the typical beam at the end of the strengthened steel element ( $\cap$-shape) due to the concentrated stresses at the end of the strengthened elements and this may need to increase the length of the strengthened element. Also this figure indicated that there was no apparent bond failure between the composite (GFRP) and the steel box beam on either side of the failure section in the case of SB5 beam, therefore complete composite action, between the two components. On the other hand, in the two strengthened beams with CFRP; SB6 and SB7, there were local failure occurred at the locations of the applied load. There was intermediate debonding followed by fiber breakage at the location of the load without complete debonding due to the CFRP sheet was wrapped around the steel box beam.

The effect of strengthened methods for box steel beams are presented and discussed in the current sections (see Fig. 16 to Fig 21). Fig. 16 and Fig 17 shows the experimental load-deflection curves at mid-span and at dial point 2; respectively of all tested beams in comparing with the control beam. Fig. 18 and Fig 19 present relationship between all 
tested beams in terms of the ultimate and mid-span deflection. From these figures, it can be seen that the two strengthened beams SB5 and SB6 have the same behavior; their ultimate loads are greater than that of the control beam by about $11 \%$ while SB1 and SB2 beams achieve an increase in the ultimate load by about 3.5\% than the ultimate load of the control beam. Beam SB7 enhances the yield and ultimate loads by about 57\% and $43 \%$; respectively in comparing with the control beam. SB3 beam showed enhancement in the yield and the ultimate load by about $57 \%$ and $96 \%$; respectively while SB4 beam increases the yield load and ultimate load by about $102 \%$ and $108 \%$; respectively than the control beam. Also SB5 beam gives the biggest deflection at the ultimate load. Fig. 20 indicates the load-strain curves for all tested beam from the experimental work. This figure showed that SB3 gives the least strain. Fig. 21 showed that the maximum normal stresses in all tested beam are at the locations of the loading and their surrounding areas.
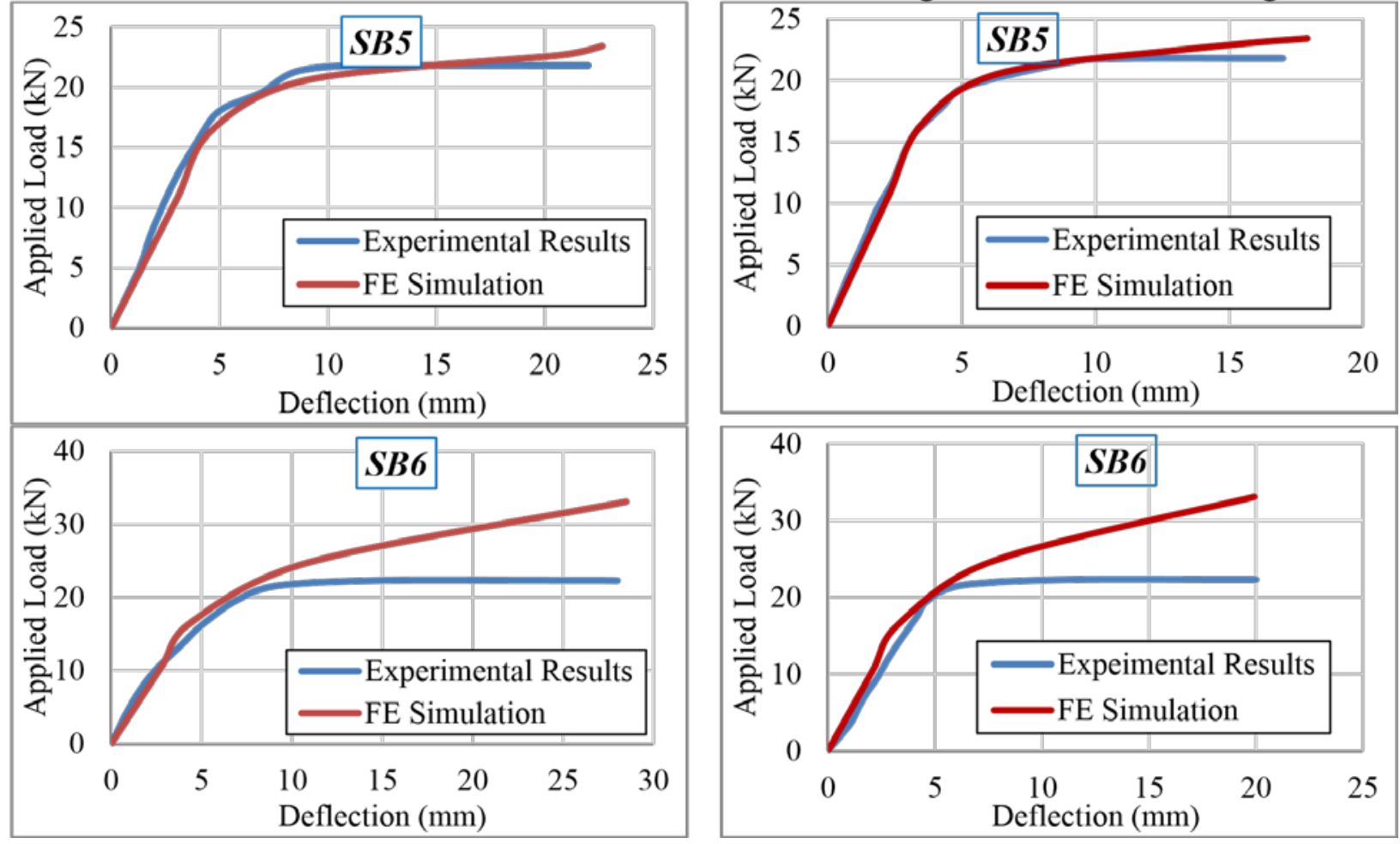

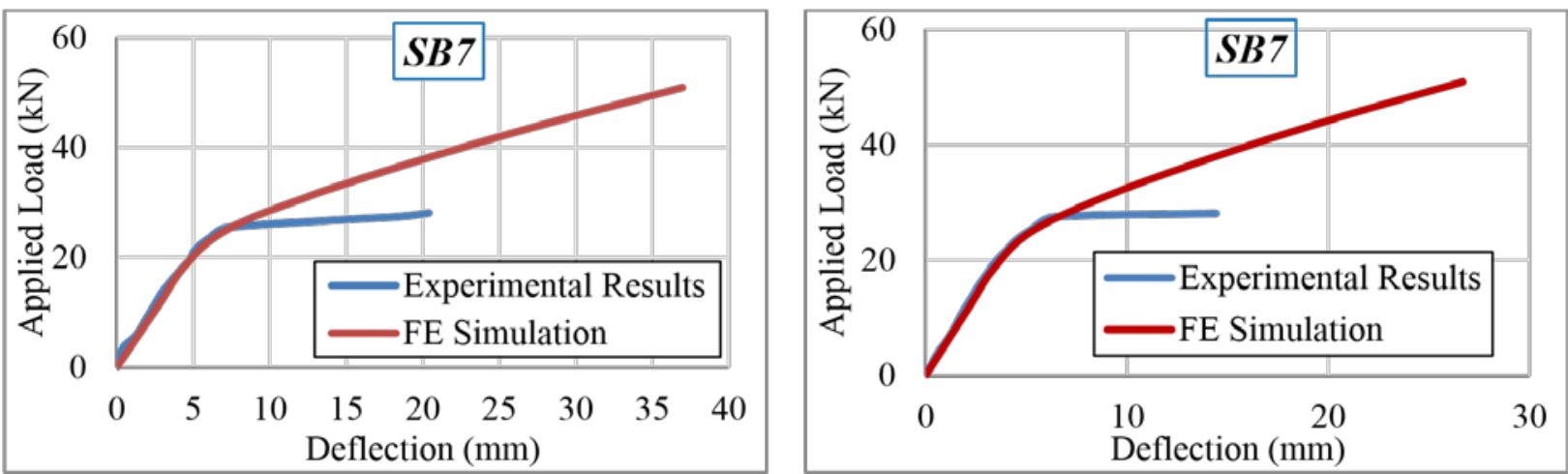

Fig. 13: Experimental and FE simulation total load-deflection curves for strengthened beam with composite materials; left at dial 1 and right at dial 2
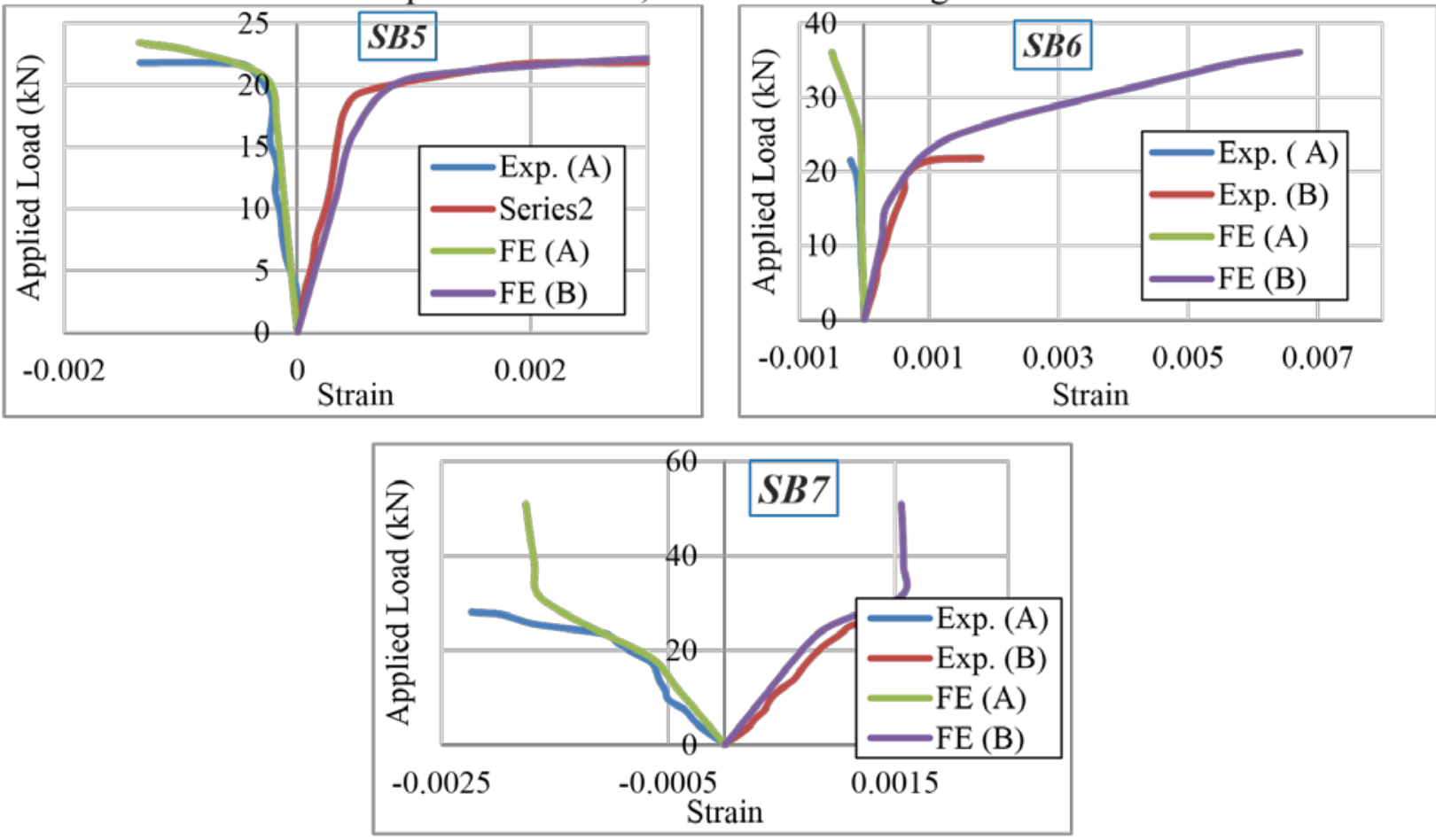

Fig. 14: Total load-strain curves for strengthened beam with composite material 


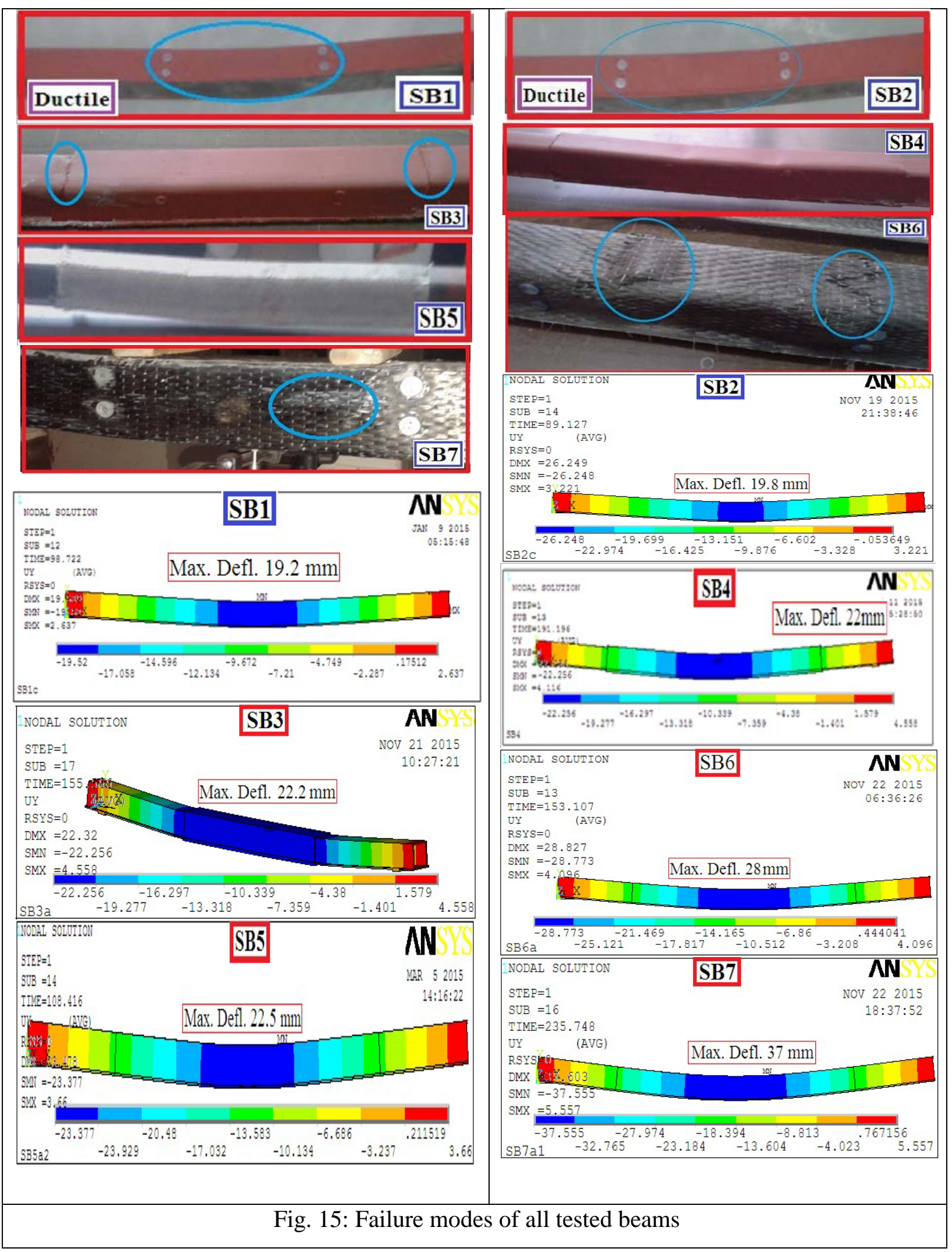




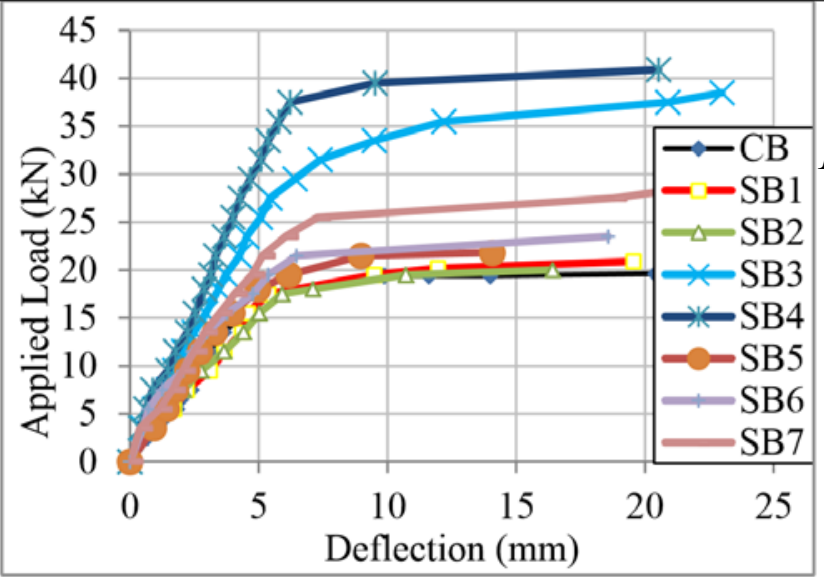

Fig. 16 Load-deflection curves at the midspan for all tested beams

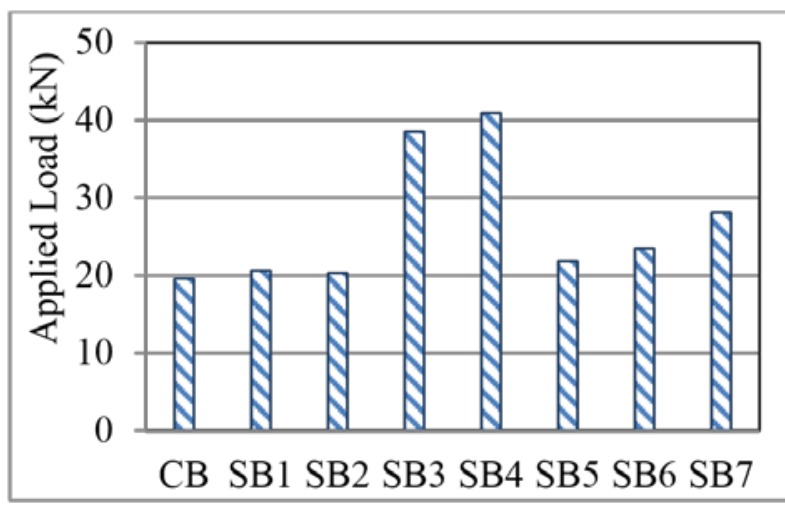

Fig. 18: Failure load for tested beam

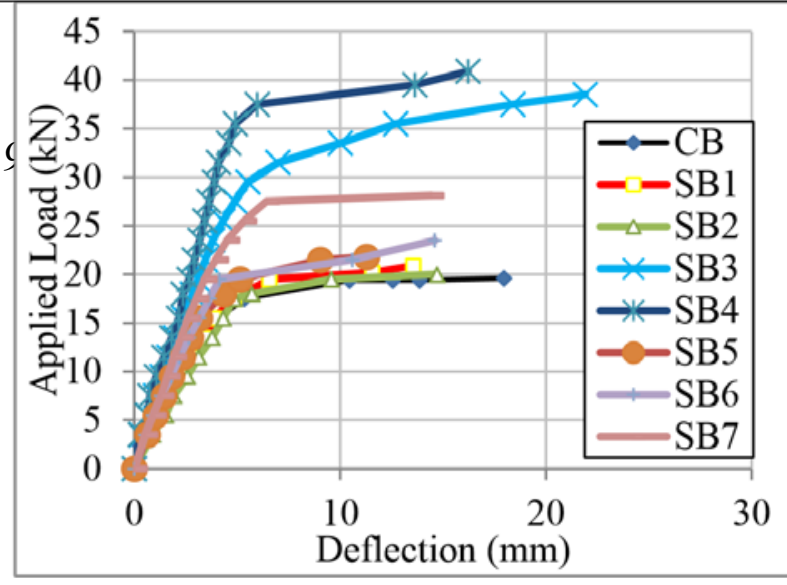

Fig. 17 Load-deflection curves at dial (2) point for all tested beams

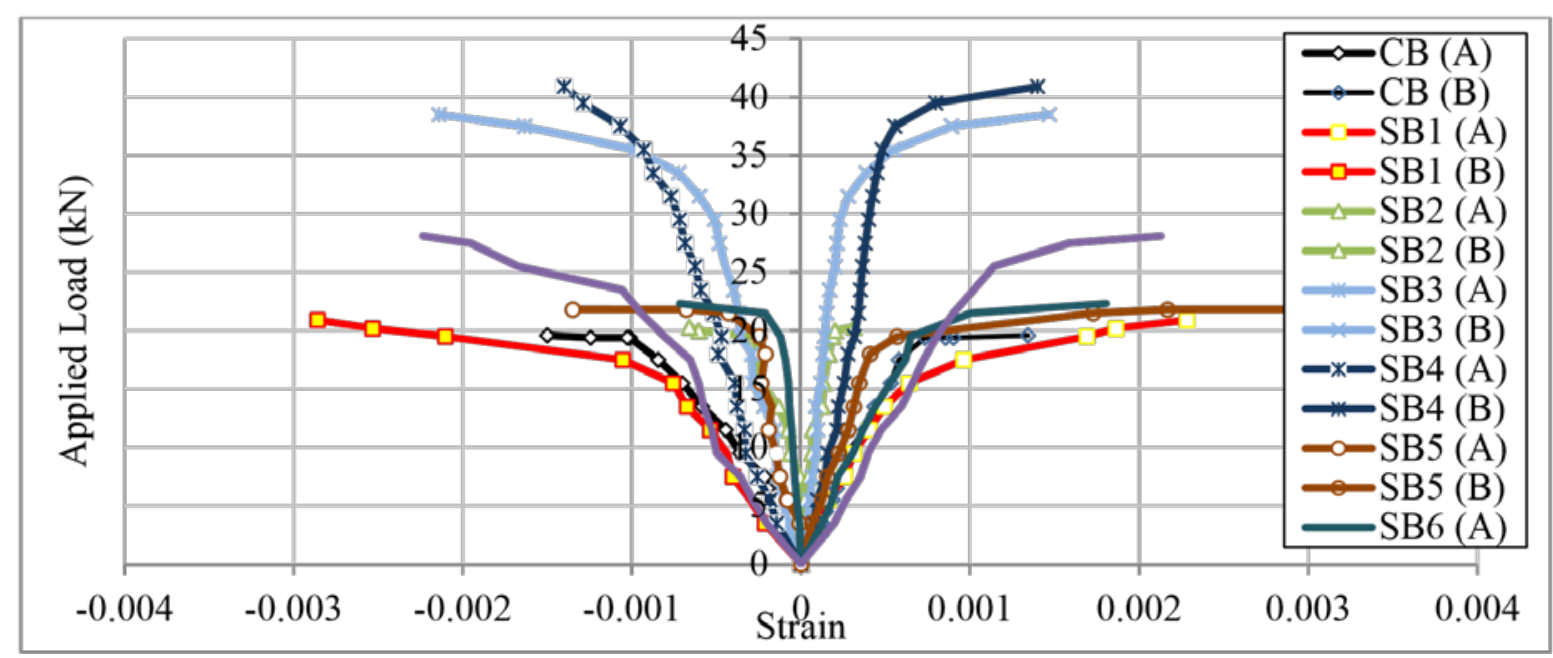

Fig. 20: Load- strain behavior for all tested beams 


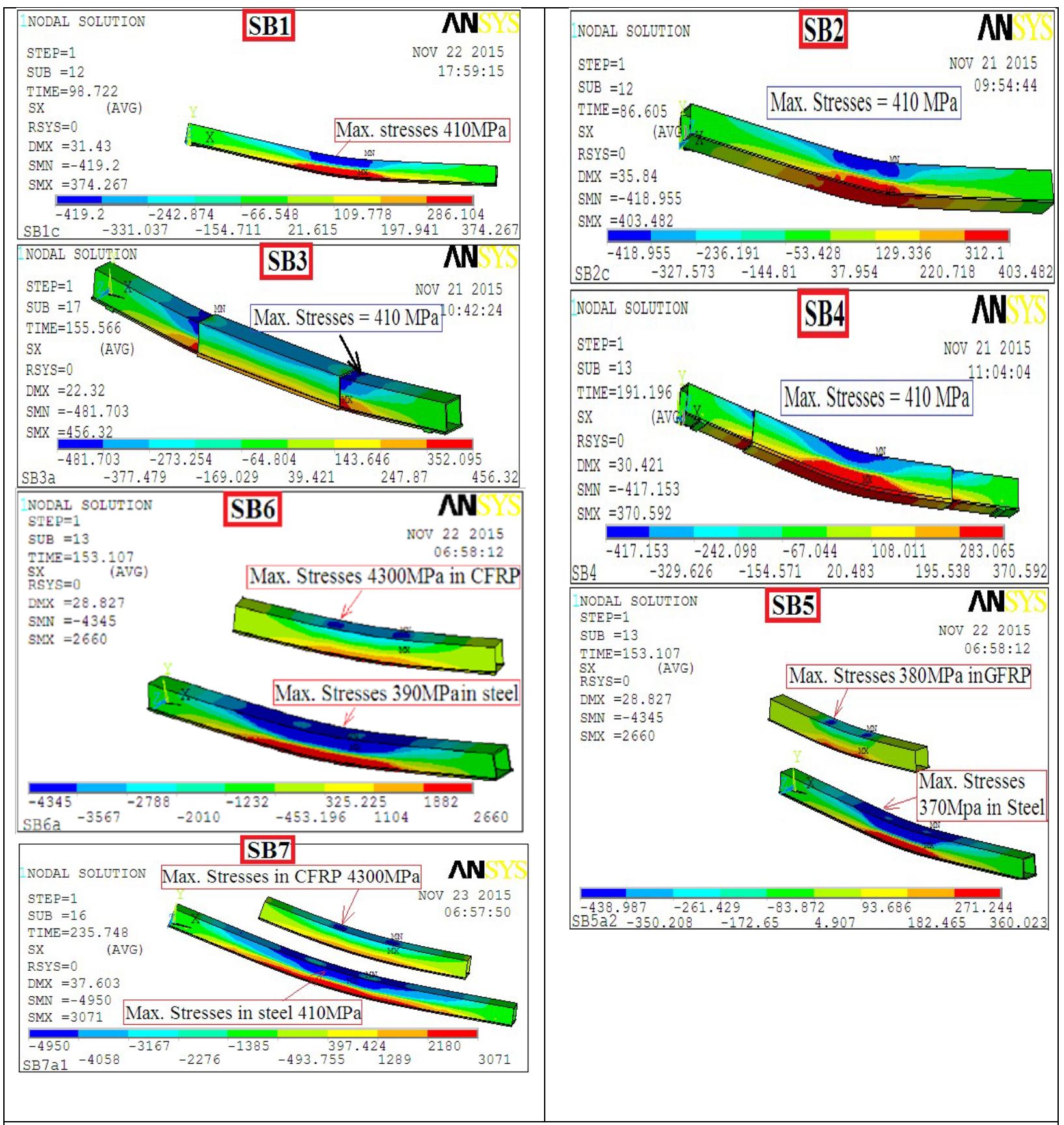

Fig. 21: Numerical normal stresses distribution for strengthened beams at the ultimate load

\section{Conclusions}

The current research presents experimental and numerical study for eight steel box beams (typical beam and seven strengthened beams) under flexural to investigate the suitable method to strengthen the box steel beam under concentrated loads. Based on these studies, the following conclusions are drawn:

1) The FE simulations give acceptable results in comparing with the experimental results in case of the control beam and strengthened beam with steel elements and GFRP. 
2) The employing numerical model gives closed results in the linear stage comparing with the experimental and it gives a difference results in non-linear stage in comparing with the experimental results.

3) The failure mode of the control beam and strengthen beam with steel elements are ductile mode failure. Additionally in the case of SB3 beam, there was local failure in the typical beam at the end of strengthened elements in top flange.

4) There was complete composite action between the steel and GFRP in SB5 beam.

5) Intermediate debonding followed by fiber breakage at the location of the load (in the top flange and the upper part of the two webs) was occurred in the two strengthened beams with CFRP.

6) Strengthening the steel box beam with -shaped steel plate and flat plate gives the best structural performance.

7) By increasing the numbers of CFRP layers, the structure behavior of the steel box beam increased.

8) SB1 and SB2 beams do not enhance a clear increasing in the ultimate load than the control beam.

\section{References}

1) Al-Saidy, A. H., Klaiber, F. W., Wipf, T. J., (2005), "Repair of steel composite beams with carbon fiber reinforced polymer plates," Journal of Composite Construction, Vol. 2, No. 8, pp. 163- 72.

2) ANSYS, (2009), “ANSYS Help,” Release 12.0, Copyright.

3) Bakht, B., Sweeney, R. A. P., Saunders, W. W., Yule, R. B., Byers, W. G., Mosese, F., McKeel, W. T., Higgins, M., Kahn, L., and Heins, C. P. (1979), "Repair and strengthening of old steel truss bridges,” American Society of Civil Engineers, New York. P. 137.

4) Colombi, P., Poggi, C., (2006a), “An experimental, analytical and numerical study of the static behavior of steel beams reinforced by pultruded CFRP strips," Journal of Composite Part (B), Vol. 1, No. 32, pp. 64-73.

5) Colombi, P., and Poggi, C., (2006b), "Strengthening of tensile steel members and bolted joints using adhesively bonded CFRP plates." Journal of Construction and Building Materials, Vol. 1, No. 20, pp. 22-33.

6) Deng, J., and Lee, M. M. K., (2007), "Behavior under static loading of metallic beams reinforced with a bonded CFRP plate,” Journal of Composite Structures, Vol. 2, No. 78, pp. 232-242.

7) El Damatty, A. A., Abushagur, M., and Youssef, M. A., (2003), "Experimental and analytical investigation of steel beams rehabilitated using GFRP sheets.” Journal of Steel and Composite Structures, Vol. 6, No. 3, pp. 421-438.

8) Hmidan, A., Kim, Y., and Yazdani, S., (2013), "Crack-dependent response of steel elements strengthened with CFRP sheets," Journal of Construction and Building Materials, Vol. 49, pp.110-120. 
9) Kadhim, M., (2012), "Effect of CFRP plate length strengthening continuous steel beam," Journal of Construction and Building Materials, Vol. 28, pp. 648-652.

10) Jagtap, P. R., Pore, S. M., and Prakash, V., (2015), "Necessity of strengthening of steel structures with FRP composites: a review," International Journal of Latest Trends in Engineering and Technology (IJLTET), Vol. 5, Issue 4, pp. 390-394.

11) Lam, C. A., Cheng, J. R., and Yam, C.H.M. (2004), "Study of the tensile strength of CFRP/steel double lap joint," $4^{\text {th }}$ International Conference on Advanced Composite Materials in Bridges and Structures, July 20-23, Calgary, Alberta.

12) Lenwari, A., Thepchatri, T. and Albrecht, P., (2006), "Debonding strength of steel beams strengthened with CFRP plates,” ASCE Journal of Composites for Construction, Vol. 10, No. 1, January/February, pp. 69-78.

13) Linghoff, D., Al-Emrani, M., and Kliger, R., (2006), "Strengthening steel beams using bonded carbon-fibre-reinforced-polymers laminates," Proceedings of the $3^{\text {rd }}$ International Conference on Bridge Maintenance, Safety, and Management IABMAS’06. Porto, Portugal, July 16-19, 2006.

14) Michael J. Chajes, M. J., Chacon, A.P., and Swinehart, M. W., Richardson, D. R. Wenczel and Liu, W., (2005) “Applications of advanced composites to steel bridges," Technical Report, Delaware Center for Transportation, University of Delaware, Newark, Delaware.

15) Narmashiri, K., and Jumaat, M. Z., (2011), "Reinforced steel I-beams: A comparison between 2D and 3D simulation,” Journal of Simulation Modeling Practice and Theory, Vol. 19, pp. 564-585.

16) Ochi, N., Matsumura, M., and Hisabe, N., (2011), “Experimental study on strengthening effect of high modulus CFRP strips with different adhesive length installed onto the lower flange plate of I shaped steel girder,” Journal of Procedia Engineering, Vol. 14, pp. 506-512.

17) Photiou, N. K., Hollaway, L. C., and Chryssanthopoulos, M. K., (2006a), "Selection of carbon-fiber-reinforced polymer systems for steelwork upgrading," Journal of Materials in Civil Engineering, ASCE, Vol. 5, No. 18, pp. 641-649.

18) Photiou, N. K., Hollaway, L. C., and Chryssanthopoulos, M. K., (2006b), "Strengthening of an Artificial Degraded Steel Beam Utilizing a Carbon/Glass Composite System," Journal of Construction and Building Materials, Vol. 20, No. 1-2, pp. 11-21.

19) Salama, T., and Abd-El-Meguid, A., (2010), "Strengthening steel bridge girders using CFRP,” Technical Report, University Transportation Center for Alabama (UTCA), The University of Alabama, Birmingham, No. 06217, June.

20) Schnerch, D., Dawood, M., Rizkalla, S., and Sumner, E., (2007), "Proposed design guidelines for strengthening of steel bridges with FRP materials," Journal of Construction and Building Materials, Vol. 2, pp. 1001-1010.

21) Shaat, A., "Structural behavior of steel columns and steel-concrete composite Girders Retrofitted Using CFRP,” Ph. D, Thesis, Queen’s University, Kingston, Ontario, Canada, November, 2007.

22) Shaat, A., and Fam, A., (2006), “Axial loading tests on short and long hollow structural steel columns retrofitted using carbon fiber reinforced polymers,” Canadian Journal of Civil Engineering, Vol. 4, No. 33, pp. 458-470. 
23) Shaat, A., and Fam, A., (2009), "Slender steel columns strengthened using high- modulus CFRP plates for buckling control," Journal of Composites for Construction (ASCE), Vol. 1, No. 13, pp. 2-12.

24) Tavakkolizadeh, M., and Saadatmanesh, H., (2003), "Strengthening of steel-concrete composite girders using carbon fiber reinforced polymers sheets," Journal of Structural Engineering (ASCE), Vol. 1, No. 129, pp. 30-40.

25) Teng, J. G., Yu, T., and Fernando, D., (2012), "Strengthening of steel structures with fiber-reinforced polymer composites,” Journal of Constructional Steel Research, No. 78, pp. 131-143.

26) Yu, Y., Chiew, S. P. and Lee, C. K., (2011), “Bond failure of steel beams strengthened with FRP laminates - Part 2: verification,” Journal of Composites: Part B, Vol. 42, pp. 1122-1134. 